\title{
In vitro evaluation of surface topographic changes and nickel release of lingual orthodontic archwires
}

\author{
Carlos Suárez • Teresa Vilar · Javier Gil • \\ Pablo Sevilla
}

Received: 11 July 2009/Accepted: 2 October 2009/Published online: 14 October 2009

(C) Springer Science+Business Media, LLC 2009

\begin{abstract}
The objective of the article is to study surface topographic changes and nickel release in lingual orthodontic archwires in vitro. Stainless steel (SS), nickel-titanium (NiTi) and copper-nickel-titanium (CuNiTi) lingual orthodontic archwires were studied using atomic absorption spectrometry for nickel release after immersion in a saline solution. Surface roughness changes were measured using atomic force microscopy. Differences between groups were analyzed using independent sample $t$-tests. Statistically significant changes in roughness were seen in all archwires except NiTi. Surface changes were most severe in the CuNiTi alloy. SS archwires released the highest amount of nickel. In conclusion, only roughness changes in CuNiTi archwires seemed to be clinically significant. The amount of nickel released for all archwires tested is below the levels known to cause cell damage.
\end{abstract}

C. Suárez $(\bowtie)$

Division d'Orthodontie, Section de Médecine Dentaire, Faculté de Médecine, Université de Genève, Rue Barthélemy-Menn, 19, 1205 Geneva, Switzerland

e-mail: carlosuarezmartinez@gmail.com

T. Vilar

Departament d'Odontoestomatologia, Facultat d'Odontologia, Universitat de Barcelona, c/Feixa Llarga, s/n, 08907

L'Hospitalet de Llobregat, Spain

J. Gil · P. Sevilla

Departament de Ciència dels Materials i Enginyeria

Metal-lúrgica, Escola Tècnica Superior d'Enginyeria Industrial,

Universitat Politècnica de Catalunya, Avda. Diagonal, 647, 08028 Barcelona, Spain

\section{Introduction}

It is known that surface topography of orthodontic archwires is an essential functional property that influences the mechanical characteristics of orthodontic appliances, their corrosion behaviour, and therefore their biocompatibility [1].

Orthodontic appliances are commonly made of alloys such as stainless steel (SS), Chromium-Cobalt NickelTitanium (NiTi) and other alloys containing titanium, for example Nickel-Titanium-Copper (NiTiCu) and Titanium-Molybdenum (TMA). The oral cavity is a harsh environment for orthodontic archwires. Some studies confirm that the concentrations of $\mathrm{Cl}$-ions commonly found in saliva are able to induce corrosive transformations in stainless steel [2]. Moreover, fluorides contained in toothpastes and mouthwashing solutions are known to induce corrosive changes in SS and NiTi archwires [3-8].

Corrosion of orthodontic appliances has concerned clinicians for some time as two principal issues are related to this phenomenon [9]. First, corrosion products can cause local and systemic problems like allergic reactions after being in contact or being absorbed by the organism. Secondly, physical properties of orthodontic appliances are affected by corrosion, reducing their clinical performance.

In orthodontics, SS is normally used in its austenitic type as an $18-8$ alloy (18\% chromium and $8 \%$ nickel). It is known as American Iron and Steel Institute type 304 [10]. NiTi alloys used in orthodontics present an almost equiatomic percentage of nickel and titanium. Depending on the manufacturer, the content in nickel may range from 51.3 to $57 \%$ and the content of titanium from 43 to $48.7 \%$ [6, 11-15]. In NiTiCu alloys, the $\mathrm{Cu}$ content ranges from 5.5 to $6.9 \%[7,14,16]$. Commercially available 
presentations of $\mathrm{NiTiCu}$ archwires are commonly referred to as CuNiTi in orthodontic literature and daily clinical practice.

The adverse effects of $\mathrm{Ni}$ inflicts have been widely documented suggesting that it is responsible for allergic reactions (more severe than those induced by other elements) and toxic interactions [17-21]. Some studies have found nickel as a possible carcinogenic element [22-24] while others have failed to determine carcinogenic effects derived from it $[25,26]$. Although in orthodontics $\mathrm{Ni}$ represents the main concern as long as toxicity and allergy is concerned, other ions released from appliances also have toxic effects. Evidence shows that metal ions like $\mathrm{Ni}$ released during orthodontic treatment are far below the levels acquired by ingestion from a routine daily diet [9].

The way in which mechanical characteristics of archwires are affected by corrosion is controversial. It seems that fluorides used as topical agents reduce the functional unloading mechanical characteristics of NiTi [3], and that they facilitate hydrogen embrittlement that may be responsible for reducing the tensile strength to critical stress levels that lead to fracture [5]. Other studies simply highlight surface finishing differences as responsible for the variations in mechanical properties [27].

In the late 1970s and beginning of the 1980s, Dr. Craven Kurz et al. [28] and Kinya Fujita [29, 30] introduced lingual orthodontics as a new technique for treating malocclusions. Lingual orthodontics is sometimes referred to as invisible orthodontics. The main characteristic of this technique is the fact of bonding the brackets on the lingual and palatal surfaces rendering the appliance invisible (Fig. 1). This technique has very much evolved. Different bracket systems and archwires have been made available for this technique.

Lingually placed appliances face more demanding conditions given that treatment becomes technically more demanding for the orthodontist. It is especially important to

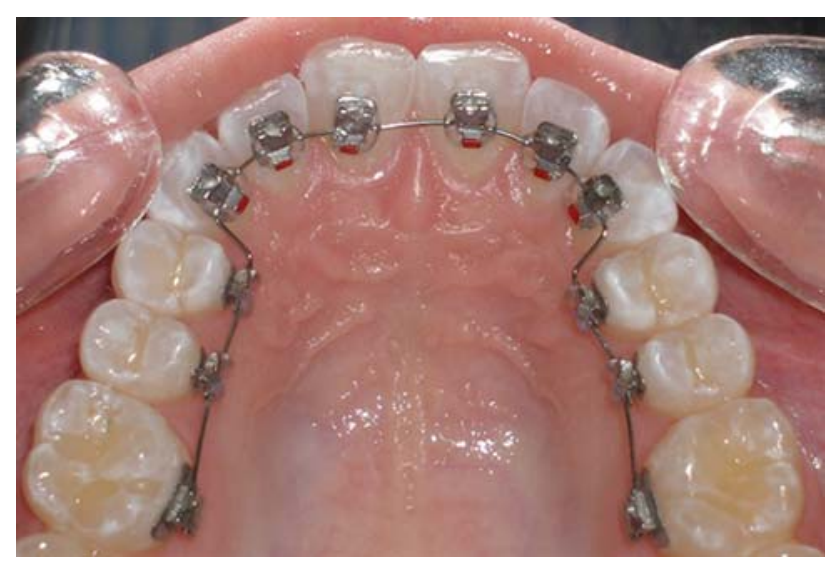

Fig. 1 Orthodontic lingual treatment of the upper arch understand the properties of the archwires used so as to overcome difficulties that may arise during treatment.

To our knowledge, the degradation and nickel release of lingual orthodontic archwires has yet to be studied. Our purpose is to analyze the effect that immersion of lingual orthodontics archwires in a saline solution has on its surface topography, and on the amount of nickel released. We aim to determine the baseline behaviour of these archwires prior to studying them in different corrosive environments as has already been carried out for archwires used in conventional orthodontics. The null hypothesis is that immersion of archwires in a saline solution has no effect on their surface topography. Nickel release is analyzed in order to determine to what extent it could be dangerous for the patients treated with this technique. The hypothesis is that nickel release from lingual orthodontic archwires does not differ from those used in conventional orthodontics.

\section{Materials and methods}

Six different types of lingual orthodontic archwires from the same manufacturer (Ormco Corp., Glendora, CA, USA) were chosen for this study. They represent a sequence of commonly used archwires used during a standard lingual treatment (Table 1).

Eight archwires of each type were randomly selected. Four archwires of each type were used for an immersion test in Hank's Balanced Salt Solution (HBBS, SigmaAldrich Co., 3050 Spruce Street, St. Louis, Missouri) in order to determine the level of nickel release. They were cut with sterile pliers in three segments each of which was $3 \mathrm{~cm}$ long. The method applied was that of the ISO-standard 10993-15:2000 "Biological evaluation of medical devices. Part 15: Identification and quantification of degradation products from metals and alloys". An empty vial was prepared as a blank control for Ni level measurements.

Nickel release was measured through atomic absorption spectrometry (AAS) at 7,14 and 30 days after immersion. Nickel release was measured per unit of surface area of the archwire. The surfaces corresponding to the section of the archwire were not taken into account for this purpose.

After the nickel release test, the archwires were further cut into segments of $4 \mathrm{~mm}$ so as to evaluate their surface through scanning electronic microscopy (SEM) and atomic force microscopy (AFM). Four new randomly selected archwires of each type were also cut in $4 \mathrm{~mm}$ segments in order to be microscopically compared with the immersion group. The wires were cut with sterile orthodontic pliers.

Scanning electronic microscopy images of the $4 \mathrm{~mm}$ segments (JEOL JSM-6400, Pleasanton, CA, USA) were obtained at $\times 160, \times 500$ and $\times 1,500$ magnifications for each type of archwire from both groups. The selected 
Table 1 Archwires used in the study

\begin{tabular}{lllll}
\hline Archwire & Alloy & Section (in.) & Batch number & Lot \\
\hline Respond & Stainless steel & 0.0175 & $203-0007$ & $05 \mathrm{G} 18$ \\
D-Rect & Stainless steel & $0.016 \times 0.022$ & $201-0023$ & $04 \mathrm{H} 206 \mathrm{H}$ \\
SS 0.016 & Stainless steel & 0.016 & $206-0001$ & $05 \mathrm{E} 5$ \\
SS $0.016 \times 0.022$ & Stainless steel & $0.016 \times 0.022$ & $206-0006$ & $05 \mathrm{~J} 84$ \\
NiTi & Nickel-titanium & 0.016 & $205-0023 / 0029$ & $05 \mathrm{~L} 175 \mathrm{~L}$ and 05L576L \\
CuNiTi & Copper-nickel-titanium & $0.017 \times 0.017$ & $205-0075 / 0078$ & $05 \mathrm{E} 236 \mathrm{E}$ and 05L188L \\
\hline
\end{tabular}

archwires were those with the least manufacturing surface defects. Posteriorly they were analyzed with AFM (Pacific Instruments, Pacific Nanotechnology, CA, USA). The images obtained with AFM were $20 \mu \mathrm{m} \times 20 \mu \mathrm{m}$ size. Ten randomly selected areas of $2 \mu \mathrm{m} \times 2 \mu \mathrm{m}$ image samples (avoiding manufacturing defects) were selected from each type of archwire in order to measure the surface roughness mean (RMS) for each group (immersed and nonimmersed archwires).

The statistical analysis was performed with the Statistical Package for Social Sciences (SPSS Inc., Chicago, Illinois, USA) software version 16.0.

Differences between mean values of RMS in both groups of archwires were analyzed for statistical differences using independent samples $t$-tests and the significance level was set at $P<0.05$.

\section{Results}

Scanning electronic microscopy and AFM images are shown in Figs. 2 and 3, respectively, in the as-received state and after being immersed for 30 days. Surface manufacturing defects can be seen in some of the images.

RMS measurements obtained through AFM after 30 days of immersion are shown in Table 2. The mean, standard deviation and independent sample $t$-test results are shown. Statistically significant differences at the $P<0.05$ level are labelled as *. Values were normally distributed.

All archwires, with the exception of NiTi wires show statistically significant changes in roughness between the as-received and the immersed state $(P<0.05)$. NiTi wires show similar mean and standard deviations values for both groups.

The accumulated values of Ni released by unit of surface area of the wire $\left(\mathrm{mm}^{2}\right)$ can be seen in Table 3 after 7 , 14 and 30 days of immersion. Figure 4 depicts the information contained in Table 3 .

During the first week of immersion D-Rect and CuNiTi wires showed the least amount of $\mathrm{Ni}$ release. The SS $0.016 \times 0.022$ wire released the same amount of $\mathrm{Ni}$ as the
$\mathrm{NiTi}$ wire but the $\mathrm{Ni}$ released by the Respond wire was marginally larger. At the end of the first week, the SS 0.016 wire released the highest content of $\mathrm{Ni}$ at the level of $0.00176 \mathrm{ng} / \mathrm{mm}^{2}$.

Measurements at 14 days showed that all wires released less $\mathrm{Ni}$ than during the first week of immersion. The SS archwires $(0.016$ and $0.016 \times 0.022)$ released the highest content of $\mathrm{Ni}$ followed by Respond. The accumulated content of $\mathrm{Ni}$ released by the NiTi and CuNiTi wires at the end of the second week was similar. D-Rect wire showed the lowest amount of $\mathrm{Ni}$ release during the second week, namely $0.00021 \mathrm{ng} / \mathrm{mm}^{2}$.

Measurements taken after 30 days of immersion showed that SS archwires $(0.016$ and $0.016 \times 0.022)$ released the highest amount of nickel followed by Respond and NiTi archwires with similar values. CuNiTi wires released approximately half the amount of $\mathrm{Ni}$ when compared to the SS 0.016 archwires. D-Rect wires showed the lowest $\mathrm{Ni}$ release values, these being 2.7 times lower than the SS 0.016 archwires.

\section{Discussion}

Surface topographic changes between immersed and asreceived archwires are difficult to see when SEM images are used for this purpose (Fig. 2). Even the highest magnification used $(\times 1500)$ was not enough to objectively assess changes of any kind. On the other hand, surface defects due to manufacturing could be clearly observed in most of the samples.

Atomic force microscopy allows an objective evaluation of surface topographic changes by measuring RMS. In addition, the magnification of this technique allows a better comparison between the immersed and as-received samples (Fig. 3).

Changes in RMS have been found to be statistically significant. It is important to assess to what extent these changes are clinically significant. Bourael et al. [13] established three categories of roughness for the archwires they studied with AFM. A surface was classified as smooth 
Fig. 2 Scanning electronic microscope images of archwires in as-received state and after 30 days of immersion
SS $0.016 \times 0.022$

SS 0.016
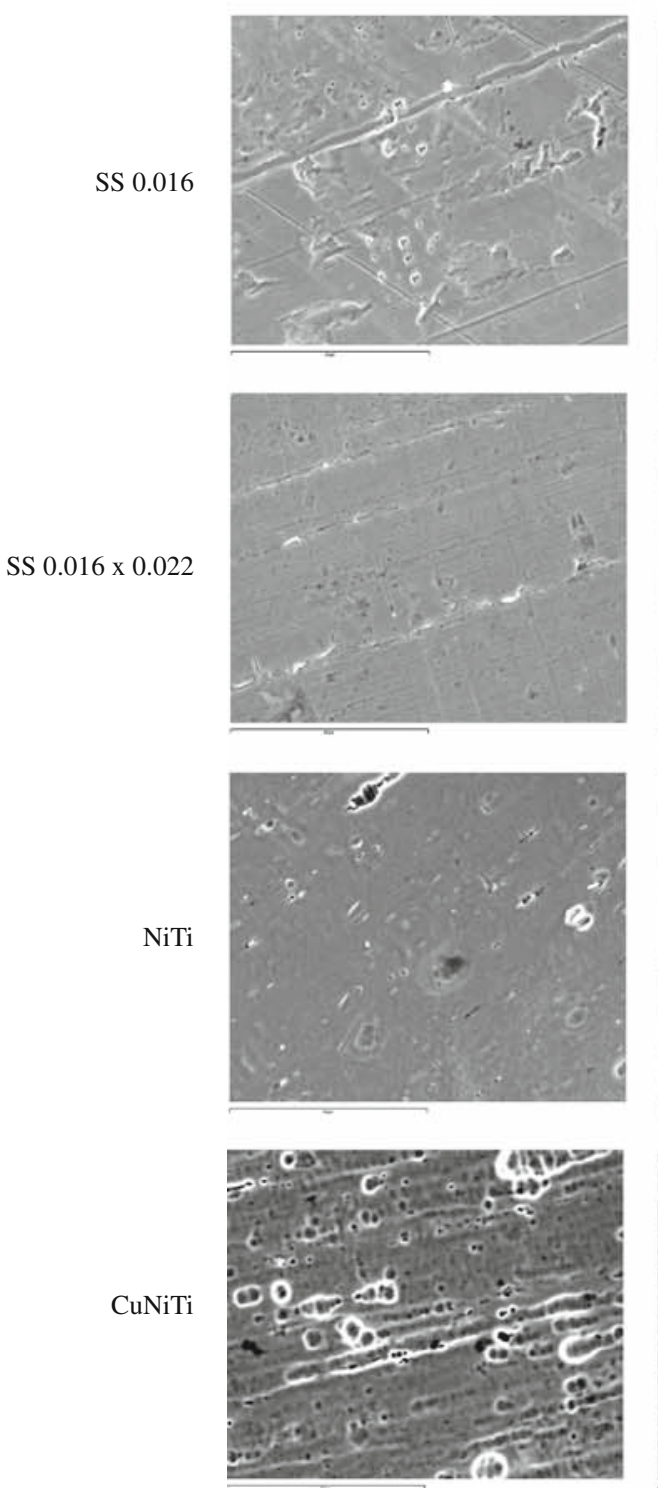
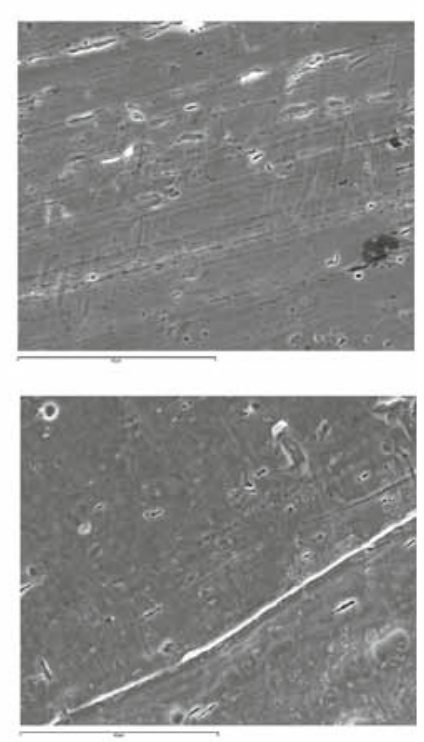

After 30 days of immersion
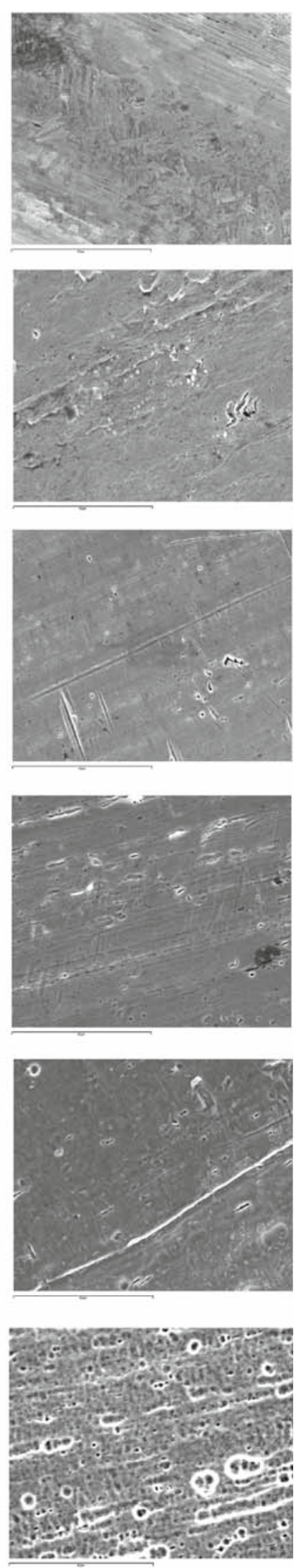
Fig. 3 Atomic force

microscopy images of archwires

in as-received state and after

30 days of immersion

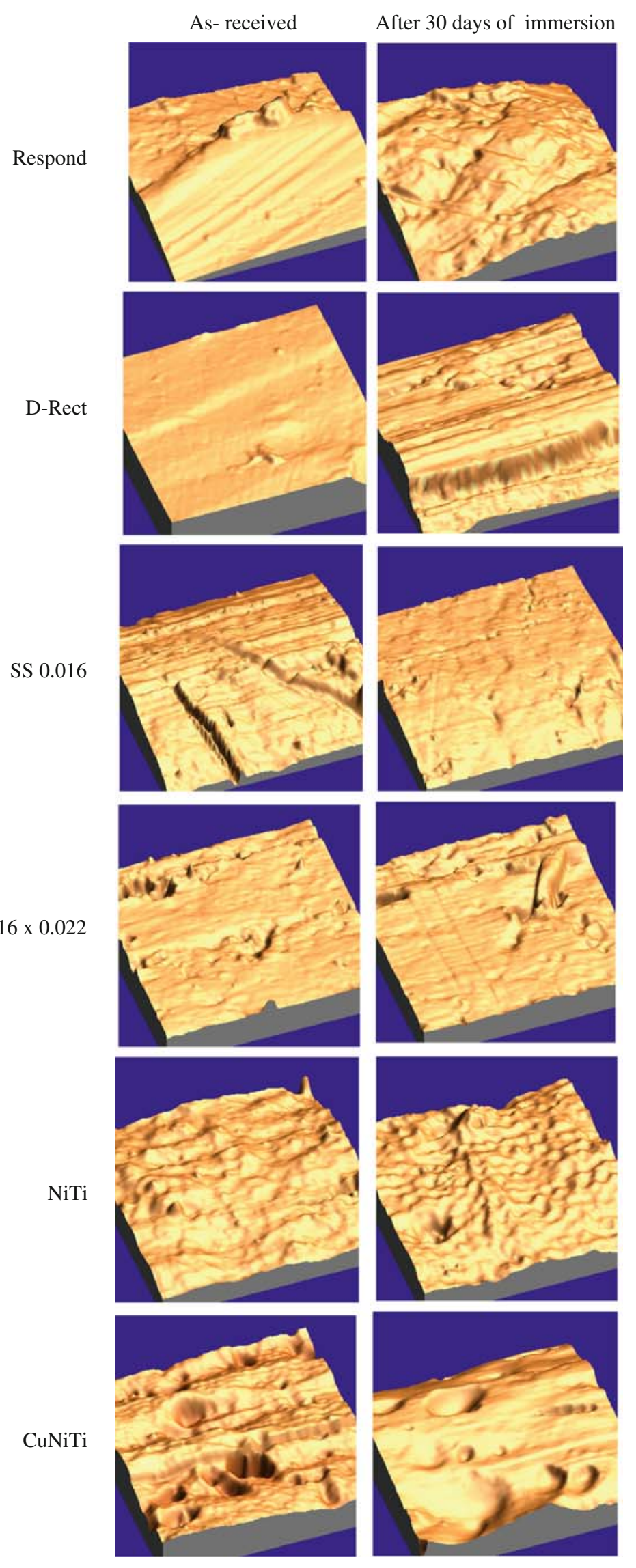

SS $0.016 \times 0.022$ 
Table 2 Descriptive statistics for rough surface mean (RMS) and $t$-test results

\begin{tabular}{|c|c|c|c|c|c|}
\hline Archwire & State & RMS mean & RMS std dev & $t$-value & $P<0.05^{*}$ \\
\hline \multirow[t]{2}{*}{ Respond } & As-received & 0.0195 & 0.0047 & \multirow[t]{2}{*}{-3.8} & \multirow[t]{2}{*}{$*$} \\
\hline & Immersed & 0.0276 & 0.0048 & & \\
\hline \multirow[t]{2}{*}{ D-Rect } & As-received & 0.0105 & 0.0027 & \multirow[t]{2}{*}{-2.01} & \multirow[t]{2}{*}{$*$} \\
\hline & Immersed & 0.0247 & 0.0219 & & \\
\hline \multirow[t]{2}{*}{ SS 0.016} & As-received & 0.0051 & 0.0008 & \multirow[t]{2}{*}{-2.73} & \multirow[t]{2}{*}{$*$} \\
\hline & Immersed & 0.0082 & 0.0035 & & \\
\hline \multirow[t]{2}{*}{ SS $0.016 \times 0.022$} & As-received & 0.0047 & 0.0008 & \multirow[t]{2}{*}{-4.97} & \multirow[t]{4}{*}{$*$} \\
\hline & Immersed & 0.0125 & 0.0048 & & \\
\hline \multirow[t]{2}{*}{ NiTi } & As-received & 0.0196 & 0.0049 & \multirow[t]{2}{*}{-0.41} & \\
\hline & Immersed & 0.0205 & 0.0044 & & \\
\hline \multirow[t]{2}{*}{ CuNiTi } & As-received & 0.0212 & 0.0051 & \multirow[t]{2}{*}{-2.71} & \multirow[t]{2}{*}{$*$} \\
\hline & Immersed & 0.0419 & 0.0236 & & \\
\hline
\end{tabular}

Table 3 Accumulated values of Ni release $\left(\mathrm{ng} / \mathrm{mm}^{2}\right)$ over 30 days

\begin{tabular}{lllllll}
\hline Days & Respond & D-Rect & SS 0.016 & SS $0.016 \times 0.022$ & NiTi & 0 \\
\hline 0 & 0 & 0 & 0 & 0 & 0.001248177 & 0.00121877 \\
7 & 0.00136857 & 0.000876848 & 0.00175822 & 0.002235658 & 0.00159779 & 0.00165581 \\
14 & 0.00187511 & 0.00109062 & 0.00298695 & 0.0087192 \\
30 & 0.00216595 & 0.001302666 & 0.00362057 & 0.002668648 & 0.00203642 & 0.00173211 \\
\hline
\end{tabular}

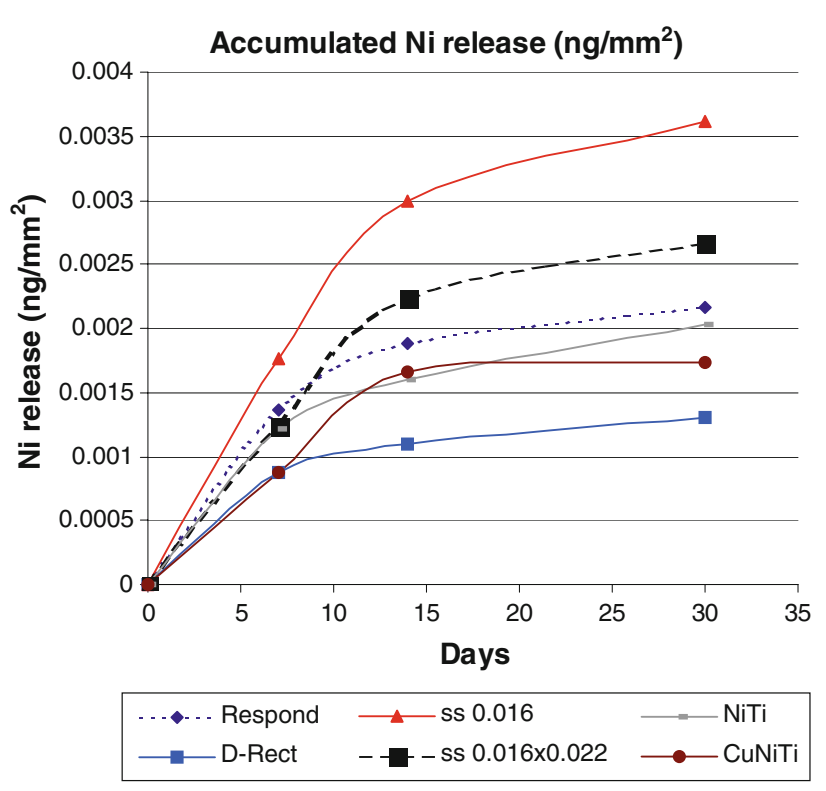

Fig. 4 Accumulated Ni release $\left(\mathrm{ng} / \mathrm{mm}^{2}\right)$ over 30 days

when RMS $<0.2 \mu \mathrm{m}$, as rough when RMS $>0.4 \mu \mathrm{m}$ and as medium when $0.2 \mu \mathrm{m}<\mathrm{RMS}<0.4 \mu \mathrm{m}$. According to this reference, the immersion of the archwires in the solution led the Respond wire surface to change from a smooth to a medium rough surface, while the D-Rect wire surface experienced the same change to a smaller extent. These changes are clinically significant. Although changes in RMS are statistically significant for SS 0.016, SS $0.016 \times 0.022$ and NiTi archwires, the values remain in the smooth category as defined by Bourael et al. [13]. Finally, CuNiTi archwires showed the biggest change in terms of RMS, shifting from almost smooth values to values considered rough. In order to study the clinical impact that this kind of change can inflict on treatment, different studies such as friction analysis should be performed.

The null hypothesis can then be rejected for all archwires except for the NiTi archwires.

Widu et al. [31] did not find significant differences between the RMS values for some of the NiTi archwires tested under a corrosive environment. On the contrary, they observed a smoothening of the surface and they hypothesized that this could be a consequence of the flattening of peaks and troughs on the surface that results from the production process.

Surface roughness of dental materials is of utmost importance, as this determines the area of surface contact and it may affect the performance of sliding mechanics by its influence on the friction coefficient [13]. Consequently, frictional forces could reduce orthodontic force by $50 \%$ or more [32]. The loss due to friction depends above all on the material parameters of the guiding archwire [13]. 
As far as Ni release results are concerned, our findings are in agreement with those obtained by Barrett et al. [33]. They observed that $\mathrm{Ni}$ release reached a maximum after 1 week and this rate decreased for the following 3 weeks for both SS and NiTi archwires. Some studies however show a higher Ni release amount than that obtained in the present study, ranging from 17.1 to $44.2 \mu \mathrm{g}[34,35]$. On the other hand, other studies [36] have found $\mathrm{Ni}$ release values ranging from 0.4 to $4.1 \mathrm{ppb}$, which are lower than those found in the present study. Archwires studied were manufactured by different companies. This fact has been shown to influence the results obtained [37] and explain their differences.

Two values are of use in order to put the results of $\mathrm{Ni}$ released in context and see the impact that they may have on patients. The first value is that stated by the regulation of the European Union concerning Ni release by utensils and jewelry items. This value is set at $0.5 \mu \mathrm{g} / \mathrm{cm}^{2}$ of material surface per week for at least two years $(0.714$ $\mathrm{ng} / \mathrm{mm}^{2}$ on a daily basis) [38]. The second value is the concentration known to impair the chemotaxis of leucocytes and stimulate neutrophils to become aspherical and move slowly (2500 $\mathrm{ng} / \mathrm{l}$ or ppb) [39].

The amount of Ni released is far below the daily limits established by the European Union [38] as seen in Table 3. The archwires studied would need to stay in contact with the solution for many years in order to reach the maximum daily value if the Ni release rate of the last month remained constant: CuNiTi (409 years), D-Rect (147 years), Respond (107 years), SS $0.016 \times 0.022$ (72 years), NiTi (71 years) and SS 0.016 (49 years).

The highest amount of Ni release seen in this study is not even $1 / 10$ of the amount of Ni required to inflict cell damage as found in other studies [39].

An interesting finding is the fact that SS wires (typically containing $8 \% \mathrm{Ni}$ ) release more $\mathrm{Ni}$ than $\mathrm{NiTi}$ and $\mathrm{NiTiCu}$ archwires (which have around $50 \% \mathrm{Ni}$ in content). A study by Hwang et al. [40] already obtained similar results. Unfortunately this fact is not often highlighted.

Although other ions can be released from orthodontic appliances, most of the attention has been focused in studying Ni effects. As literature reveals, less attention has been paid in orthodontics to the effect that copper $(\mathrm{Cu})$ may have on the patient. As far as orthodontics is concerned, cytotoxicity has been evaluated on $\mathrm{NiTiCu}$ shape memory alloys on human fibroblasts showing certain toxicity [41]. A study on biocompatibility of alloys used in orthodontics did not find $\mathrm{Cu}$ as the highest cytotoxic ion but rather $\mathrm{Ag}$ and $\mathrm{Pd}$ [42]. Recent studies show that $\mathrm{CuO}$ induced the highest amount of cytotoxicity in a dose dependent manner compared to other commonly found metal oxides [43]. Other studies have shown that concerning the ability of the particles to cause cell death, mitochondrial damage, DNA damage and oxidative DNA lesions, $\mathrm{CuO}$ nanoparticles show that the nanolevel gives rise to specific concern [44]. It is also important to recall that in vitro and animal data support copper toxicity as one of the relevant mechanisms in Alzheimer's disease [45]. Therefore, further studies should be carried looking into the role that $\mathrm{Cu}$ may play in orthodontics as regards cytotoxicity.

The present investigation studies archwires in a noncorrosive environment. The in vitro conditions that were created are not identical to conditions that can be found in vivo. Degradation of orthodontic materials has been studied using different laboratory set-ups [46-48] but accelerated corrosive experiments or experiments performed in a non-corrosive environment cannot reliably simulate the oral environment in any case.

The results obtained in the present study should therefore be interpreted with that in mind. This study helps to understand the baseline behaviour of these kind of archwires so that, in the future, experiments with corrosive set-ups can be carried out, which may be closer to this in vivo situation. Furthermore, future studies investigating archwires retrieved from patients treated with lingual orthodontics can be used to better describe their corrosive behaviour.

\section{Conclusions}

Archwires used in lingual orthodontics show significant changes in surface topography when they are immersed in a non-corrosive environment. The null hypothesis can then be rejected for all archwires except for the NiTi archwires. Despite this, only changes in surface roughness of $\mathrm{NiTiCu}$ archwires seem to be clinically significant.

The amount of $\mathrm{Ni}$ that these archwires release in the testing environment used is negligible and it is far below the levels known to induce cell damage. The archwires that released the highest amount of $\mathrm{Ni}$ are the stainless steel archwires.

Acknowledgements The present study was funded through a research grant of the Universitat de Barcelona (Facultat d'Odontologia). We would like to acknowledge the help provided in the Universitat Politècnica de Catalunya by Dr. José María Manero and Fernando Villar in obtaining the images for the present study. The photo in Fig. 1 was kindly donated by Dr. A. Hayes (St Louis, MO, USA). We are especially grateful to Dr. Gregory Stylianos Antonarakis from the Division of Orthodontics of the Université de Genève for proof reading this manuscript.

\section{References}

1. Daems J, Celis JP, Willems G. Morphological characterization of as-received and in vivo orthodontic stainless steel archwires. Eur J Orthod. 2009;31:260-5. 
2. McCann HC. Inorganic components of salivary secretions. In: Harris RS, editor. Art and science of dental caries research. New York: Academic Press; 1968. p. 55-70.

3. Walker MP, White RJ, Kula KS. Effect of fluoride prophylactic agents on the mechanical properties of nickel-titanium-based orthodontic wires. Am J Orthod Dentofac Orthop. 2005;127:662-9.

4. Kaneko K, Yokoyama K, Moriyama K, Asaoka K, Sakai J. Degradation in performance of orthodontic wires caused by hydrogen absorption during short-term immersion in $2.0 \%$ acidulated phosphate fluoride solution. Angle Orthod. 2004;74:487-95.

5. Yokohama K, Kaneko K, Ogawa T, Moriyama K, Asaoka K, Sakai J. Hydrogen embrittlement of work-hardened Ni-Ti alloy in fluoride solutions. Biomaterials. 2005;26:101-8.

6. Schiff N, Grosgogeat B, Lissac M, Dalard F. Influence of fluoridated mouthwashes on corrosion resistance of orthodontic wires. Biomaterials. 2004;25:4535-42.

7. Ogawa T, Yokoyama K, Asaoka K, Sakai J. Hydrogen absorption behavior of beta-titanium alloy in acid fluoride solutions. Biomaterials. 2004;25:2419-25.

8. Kaneko K, Yokoyama K, Moriyama K, Asaoka K, Sakai J, Nagumo M. Delayed fracture of beta titanium orthodontic wire in fluoride aqueous solutions. Biomaterials. 2003;24:2113-20.

9. House K, Sernetz F, Dymock D, Sandy JR, Ireland AJ. Corrosion of orthodontic appliances-should we care? Am J Orthod Dentofac Orthop. 2008;133:584-92.

10. Verstrynge A, van Humbeeck J, Willems G. In vitro evaluation of the material characteristics of stainless steel and beta-titanium orthodontic wires. Am J Orthod Dentofac Orthop. 2006;130:460-70.

11. Kim H, Johnson JW. Corrosion of stainless steel, nickel-titanium, coated nickel-titanium, and titanium orthodontic wires. Angle Orthod. 1999;69:39-44.

12. Pereira MC, Pereira ML, Sousa JP. Histological effects of iron accumulation on mice liver and spleen after administration of a metallic solution. Biomaterials. 1999;20:2193-8.

13. Bourauel C, Fries T, Drescher D, Plietsch R. Surface roughness of orthodontic wires via atomic force microscopy, laser specular reflectance, and profilometry. Eur J Orthod. 1998;20:79-92.

14. Schiff N, Boinet M, Morgon L, Lissac M, Dalard F, Grosgeat B. Galvanic corrosion between orthodontic wires and brackets in flouride mouthwashes. Eur J Orthod. 2006;28:298-304.

15. Oh K-T, Kim K-N. Ion release and cytotoxicity of stainless steel wires. Eur J Orthod. 2005;27:533-40.

16. Fischer-Brandies H, Es-Souni M, Kock N, Raetzke K, Bock O. Transformation behavior, chemical composition, surface topography and bending properties of five selected $0.016 \times 0.022^{\prime \prime} \mathrm{NiTi}$ archwires. J Orofac Orthop. 2003;64:88-99.

17. McKay GC, Macnair R, MacDonald C, Grant MH. Interactions of orthopaedic metals with an immortalized rat osteoblast cell line. Biomaterials. 1996;17:1339-44.

18. Kerosuo H, Kullaa A, Kerosuo E, Kanerva L, Hensten-Petterson A. Nickel allergy in adolescents in relation to orthodontic treatment and piercing of ears. Am J Orthod Dentofac Orthop. 1996;109:148-54.

19. Berger-Gorbet M, Broxup B, Rivard C, Yahia L'H. Biocompatibility testing of Ni-Ti screw using immuno histochemistry on sections containing metallic implants. J Biomed Mater Res. 1996;32:243-8

20. Bass JK, Fine H, Cisnero CJ. Nickel hypersensitivity in the prosthodontics patient. Am J Orthod Dentofac Orthop. 1993; 103:280-5.

21. Grimsdottir MR, Hensten-Pettersen A, Kulmann A. Proliferation of nickel sensitive human lymphocytes by corrosion products of orthodontic appliances. Biomaterials. 1994;15:1157-60.

22. International Agency for Research on Cancer. Monographs on the evaluation of carcinogenic risk of chemicals to humans. Lyon, France: IARC; 1996.
23. Zhou D, Salnikow K, Costa M. Cap43, a novel gene specifically induced by $\mathrm{Ni}^{2+}$ compounds. Cancer Res. 1998;58:2182-9.

24. Salnikow K, Gao M, Voitkun V, Huang X, Costa M. Altered oxidative stress responses in nickel-resistant mammalian cells. Cancer Res. 1994;24:6407-12.

25. Grimsdottir MR, Hensten-Pettersen A, Kulmann A. Cytotoxic effect of orthodontic appliances. Eur J Orthod. 1992;14: 47-53.

26. Ryhanen J, Niemi E, Serlo W, Niemela E, Sandvik P, Pernu H, et al. Biocompatibility of nickel-titanium shape memory metal and its corrosion behavior in human cell cultures. J Biomed Mater Res. 1997;35:451-7.

27. Schwaninger B, Sarkar NK, Foster BE. Effect of long-term immersion corrosion on the flexural properties of nitinol. Am J Orthod. 1982;82:45-9.

28. Kurz C, Swartz ML, Andreiko C. Lingual orthodontics: a status report. Part 2: research and development. J Clin Orthod. 1982;16:735-40.

29. Fujita K. New orthodontic treatment with lingual bracket and mushroom archwire appliance. Am J Orthod. 1979;76:657-75.

30. Fujita K. Multilingual bracket and mushroom arch wire technique. A clinical report. Am J Orthod. 1982;82:120-40.

31. Widu F, Drescher D, Junker R, Bourauel C. Corrosion and biocompatibility of orthodontic wires. J Mater Sci Mater Med. 1999;10:275-81.

32. Drescher D, Bourauel C, Schumacher HA. Frictional forces between bracket and archwire. Am J Orthod Dentofac Orthop. 1989;96:397-404.

33. Barrett RD, Bishara SE, Quinn JK. Biodegradation of orthodontic appliances, I biodegradation of nickel and chromium in vitro. Am J Orthod Dentofac Orthop. 1993;103:8-14.

34. Park HY, Shearer TR. In vitro release of nickel and chromium from simulated orthodontic appliances. Am J Orthod. 1983; 84:156-9.

35. Kerosuo H, Moe G, Kleven E. In vitro release of nickel and chromium from different types of simulated orthodontic appliances. Angle Orthod. 1995;65:111-6.

36. Jia W, Beatty MW, Reinhardt RA, Petro TM, Cohen DM, Maze $\mathrm{CR}$, et al. Nickel release from orthodontic arch wires and cellular immune response to various nickel concentrations. J Biomed Mater Res. 1999;48:488-95.

37. Grimsdottir MR, Gjerdet NR, Hensten-Pettersen A. Composition and in vitro corrosion of orthodontic appliances. Am J Orthod Dentofac Orthop. 1992;101:525-32.

38. Delescluse J, Dinet Y. Nickel allergy in Europe: the new European legislation. Dermatology. 1994;189(2):56-7.

39. Vreeburg KJJ, de Groot K, von Blomberg BME, Scheper RJ. Induction of immunological tolerance by oral administration of nickel and chromium. J Dent Res. 1984;63:124-8.

40. Hwang CJ, Shin JS, Cha JY. Metal release from simulated fixed orthodontic appliances. Am J Orthod Dentofac Orthop. 2001; 120:383-9.

41. Gil FJ, Solano E, Peña J, Engel E, Mendoza A, Planell JA. Microstructural, mechanical and cytotoxicity evaluation of different NiTi and NiTiCu shape memory alloys. J Mater Sci Mater Med. 2004;15:1181-5.

42. Locci P, Marinucci L, Lilli C, Belcastro S, Staffolani N, Bellocchio S, et al. Biocompatibility of alloys used in orthodontics evaluated by cell culture tests. J Biomed Mater Res. 2000;51:561-8.

43. Fahmy B, Cormier SA. Copper oxide nanoparticles induce oxidative stress and cytotoxicity in airway epithelial cells. Toxicol In Vitro. 2009; Aug 19 (Epub ahead of print).

44. Karlsson HL, Gustafsson J, Cronholm P, Möller L. Size-dependent toxicity of metal oxide particles-a comparison between nano and micrometer size. Toxicol Lett. 2009;188:112-8. 
45. Quinn JF, Crane S, Harris C, Wadsworth TL. Copper in Alzheimer's disease: too much or too little? Expert Rev Neurother. 2009;9:631-7.

46. Michelberger DJ, Eadie RL, Faulkner MG, Glover KE, Prasad NG, Major PW. The friction and wear patterns of orthodontic brackets and archwires in the dry state. Am J Orthod Dentofac Orthop. 2000;118:662-74.
47. Berradja A, Willems G, Celis JP. Tribological behaviour of orthodontic archwires under dry and wet sliding conditions in vitro. Aust Orthod J. 2006;22:11-9.

48. Berradja A, Bratu F, Benea L, Willems G, Celis JP. Effect of sliding wear on tribocorrosion behaviour of stainless steel in a Ringer's solution. Wear. 2006;261:987-93. 